\title{
Statistical analysis of daily precipitation in the Bydgoszcz region
}

\author{
Waldemar Bojar ${ }^{1}$, Leszek Knopik ${ }^{1}$, Renata Kuśmierek-Tomaszewska ${ }^{2}$, Jacek Żarski ${ }^{2}$, and Wojciech Żarski ${ }^{1, *}$ \\ ${ }^{1}$ UTP University of Science and Technology, Faculty of Management, Engineering Management Department ul. Fordońska 430, \\ 85-790 Bydgoszcz, Poland \\ ${ }^{2}$ UTP University of Science and Technology, Faculty of Agriculture and Biotechnology, Department of Agrometeorology, Plant \\ Irrigation and Horticulture ul. Bernardyńska 6, 85-029 Bydgoszcz, Poland
}

\begin{abstract}
The aim of the research has been to provide a statistical analysis of precipitation in the Bydgoszcz region based on the results of the measurements taken at the Experiment Station of the UTP University of Science and Technology in Bydgoszcz, located at Mochle, about $20 \mathrm{~km}$ away from the city centre. The paper analyses the daily total precipitation throughout 43 years (1971-2013). The analysis demonstrated a high dependence of the indicators studied on the month, confirming the annual pattern typical for the transitional climate of the temperate zone. In general, it shows an advantage of the amount and variation, and less considerably - the daily precipitation frequency in summer months, as compared with the winter months. The distribution of the probability of the daily precipitation amount for each month turned out to be compliant with gamma distribution, which allows for a potential variation in the future.
\end{abstract}

\section{Introduction}

Precipitation constitutes the key meteorological yieldformation factor which directly affects the quantity and the quality of agricultural produce. Under the conditions of transitional climate of the temperate zone between oceanic and continental, characteristic for central Poland, precipitation shows a very high variation in terms of the amount and distribution in successive years. It results in yield fluctuations in successive years [1-4].

The data on precipitation conditions of the Bydgoszcz is quite extensive, however dispersed in publications on the synthesis of the climate of Poland, regions and respective locations [5-7]. One of the latest such reports has been developed by Żarski et al. [8] showing that mean multi-year precipitation make the Bydgoszcz region fall within the areas with the lowest precipitation in Poland. The precipitation shows a very high variation in time, resulting in a climatic risk to crops cultivation. However, there were noted no significant trends in the changes in total precipitation with years 1981 through 2010 .

As seen from the climate change predictions, the variation and extreme precipitation is to increase. In the simulation studies, performed according to the typical climate change scenarios GISS Model E, HadCM3 and GFDL R15, it has been demonstrated that in central Poland the precipitation variance will increase up to 20 depending on the scenario [9]. It means, on the one hand, a greater risk in the occurrence of zero- precipitation periods resulting in droughts and, on the other hand, the occurrence of excessive precipitation resulting in local floodings of fields as well as floods.

Characteristics of the precipitation conditions on agricultural production are usually provided by applying the annual, seasonal and monthly totals. However, according to Twardosz [10], the best information on climate in terms of precipitation is provided by the analysis of daily precipitation totals. Since precipitation is not a continuous meteorological parameter, the analysis allows for providing comprehensive characteristics of the precipitation regime of a given region. Daily precipitation was covered by research performed e.g. to calculate the maximum flows with the precipitation formula [11]. In the urbanized regions the daily precipitation characteristics were providing knowledge to investigate the urban heat island [12] or for practical purposes related to designing the storm drain [13]. The statistical daily precipitation analysis are also helpful for meteorological and hydrological predictions or for data generation; e.g. the report by Kuchar \& Iwański [9], applying the series of 300-year data generated with the WGENK model. As claimed by the authors, in the water block of the model using first-order Markov chains the state for a given day (day with precipitation and day with no precipitation) is determined. The amount of the daily precipitation is generated applying two-parameter gamma distribution $\Gamma(\alpha, \beta)$.

With that in mind, it seems justifiable to take up research on the statistical analysis of daily 
precipitation at the local scale; the Bydgoszcz region. Next to the knowledge providing current climate characteristics, the paper also offers a practical value due to the possibility of using the results in predicting changes in precipitation conditions in the future.

\section{Material and research methods}

The source material was made up by the results of precipitation measurements taken following the standard method at the Experiment Station of the UTP University of Science and Technology in Bydgoszcz, located at Mochle, about $20 \mathrm{~km}$ away from the city centre $\left(\phi=53013^{\prime} \mathrm{N}, \lambda=17051^{\prime} \mathrm{E}, \mathrm{h}=98.5 \mathrm{~m}\right.$ above sea level) in the poorly-urbanized and industrialized area. It is thus a measurement point free from the impact of urban anthropogenic factors representative for the Bydgoszcz region [14]. The paper analyses the daily precipitation totals in the 43-year period (1971-2013).

The statistical indicators, commonly applied in climate reports [15], such as: multi-year means, standard deviation, coefficients of variation, extreme values and the mean precipitation efficiency. The parameter stands for the sum precipitation per precipitation day, thus having eliminated zeroprecipitation days.

The paper also investigates the data describing the amount of daily precipitation in terms of probability distribution. For each month a compliance with gamma distribution has been determined. The values of unknown parameters were estimated with the highest credibility method. Testing was made with the Kolmogorov test $\lambda$ - for large statistical samples.

\section{Research results}

The multi-year mean (1971-2013) amount of the daily total precipitation in the Bydgoszcz region was $1.32 \mathrm{~mm}$. The daily means pattern in respective months was similar to the normal distribution (Fig. 1). It is typical for the transitional climate of the temperate zone, showing an advantage of summer-half-year precipitation, as compared with the winter half-year. The highest daily precipitation means are noted in July (2.39 $\mathrm{mm})$, followed by June $(1.95 \mathrm{~mm})$ and August (1.84 $\mathrm{mm})$, while the lowest - in February $(0.70 \mathrm{~mm})$, April $(0.86 \mathrm{~mm})$ and January $(0.87 \mathrm{~mm})$.

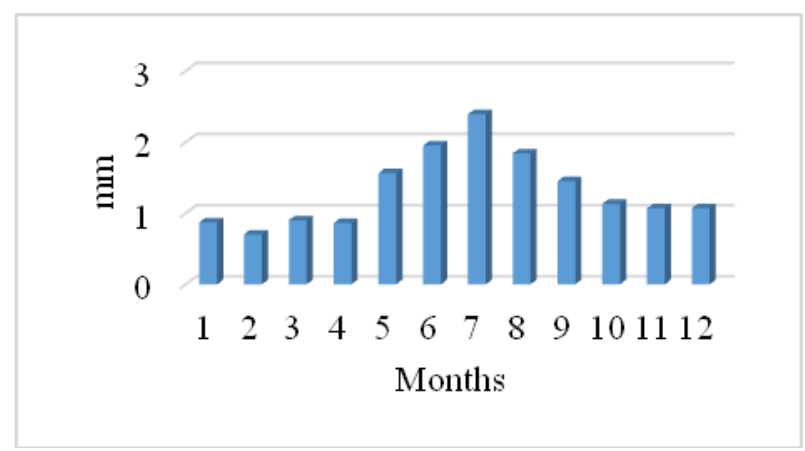

Fig. 1. Annual pattern of the mean daily precipitation totals in the Bydgoszcz region (1971-2013).
The mean daily precipitation pattern is significantly correlated with the pattern of the mean precipitation efficiency $(\mathrm{R} 2=0.9491)$. The efficiency is, on average, for the multi-year period $3.79 \mathrm{~mm}$. As for the annual pattern, it reaches the highest value in July $(5.90 \mathrm{~mm})$, followed by August $(5.47 \mathrm{~mm})$ and June $(5.12 \mathrm{~mm})$, and the lowest in February $(2.27 \mathrm{~mm})$, January $(2.58$ $\mathrm{mm}$ ) and April (2.78 mm) (Fig. 2).

The daily precipitation totals efficiency in the Bydgoszcz region showed a high variation in time. In general, one can see that the higher the mean efficiency, the wider the confidence interval, standard deviation and the coefficient of variation. The data provided in Table 1 demonstrates that the highest variation referred to the daily precipitation in July, and the lowest - in March.

The variation in precipitation is also wellcharacterised by the patterns of maximum daily precipitation. Maximum precipitation is one of the meteorological parameters providing characteristics for extreme events. As seen from Fig. 3, extremely high daily precipitation occurred in the Bydgoszcz region in the summer months. The highest daily precipitation was noted on 15 June $1980 ; 84.6 \mathrm{~mm}$, and so clearly more than the average July precipitation.

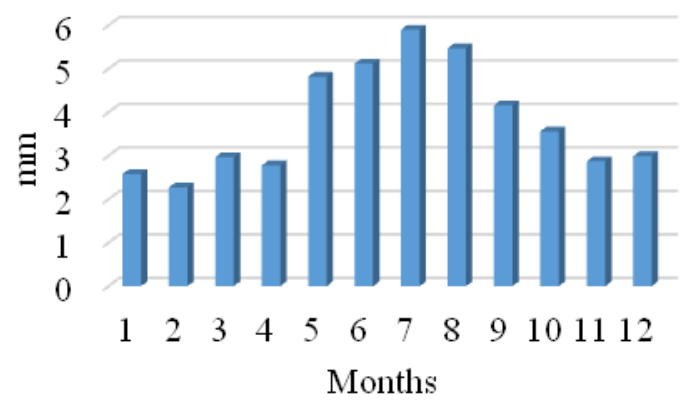

Fig. 2. Pattern of the annual mean efficiency of daily precipitation totals in the Bydgoszcz region (1971-2013).

Table 1. Statistical indicators of the variation in the mean efficiency of the daily precipitation totals in the Bydgoszcz region (1971-2013).

\begin{tabular}{|c|c|c|c|c|c|}
\hline \multirow{2}{*}{ Month } & \multirow{2}{*}{ Mean } & \multicolumn{2}{|c|}{$\begin{array}{c}95 \% \\
\text { Confidence } \\
\text { interval }\end{array}$} & $\begin{array}{c}\text { Standard } \\
\text { deviation }\end{array}$ & $\begin{array}{c}\text { Variation } \\
\text { coefficient } \\
{[\%]}\end{array}$ \\
\cline { 3 - 4 } & & $\begin{array}{c}\text { Left } \\
\text { limit }\end{array}$ & $\begin{array}{c}\text { Right } \\
\text { limit }\end{array}$ & & \\
\hline 1 & 2.58 & 2.32 & 2.83 & 2.81 & 109 \\
\hline 2 & 2.27 & 2.03 & 2.51 & 2.39 & 106 \\
\hline 3 & 2.97 & 2.69 & 3.26 & 2.94 & 99 \\
\hline 4 & 2.78 & 2.41 & 3.15 & 3.77 & 136 \\
\hline 5 & 4.82 & 4.22 & 5.42 & 6.36 & 132 \\
\hline 6 & 5.12 & 4.47 & 5.78 & 7.37 & 144 \\
\hline 7 & 5.90 & 5.18 & 6.62 & 8.53 & 145 \\
\hline 8 & 5.47 & 4.84 & 6.09 & 6.72 & 123 \\
\hline 9 & 4.16 & 3.65 & 4.66 & 5.48 & 132 \\
\hline 10 & 3.56 & 3.11 & 4.01 & 4.72 & 1.33 \\
\hline 11 & 2.87 & 2.56 & 3.18 & 3.48 & 1.21 \\
\hline 12 & 2.99 & 2.70 & 3.27 & 3.18 & 1.06 \\
\hline
\end{tabular}


Of all the 15706 days analysed, precipitation occurred on 5367 days, which means that the mean frequency of the occurrence of daily precipitation in the Bydgoszcz region accounted for $34.2 \%$, and so precipitation occurred on average every third day. The annual precipitation frequency pattern (Fig. 4) points to a greater frequency in the summer half-year (from $31.0 \%$ in April to $40.4 \%$ in July), as compared with the winter half-year (from 30.2\% in March to $37.4 \%$ in November).

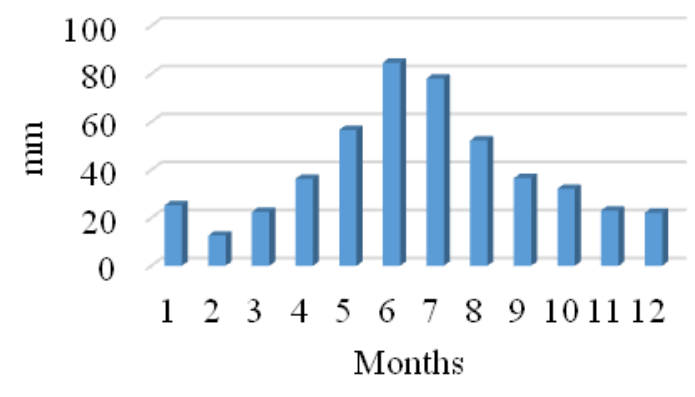

Fig. 3. Maximum daily precipitation totals in respective months in the Bydgoszcz region (1971-2013).

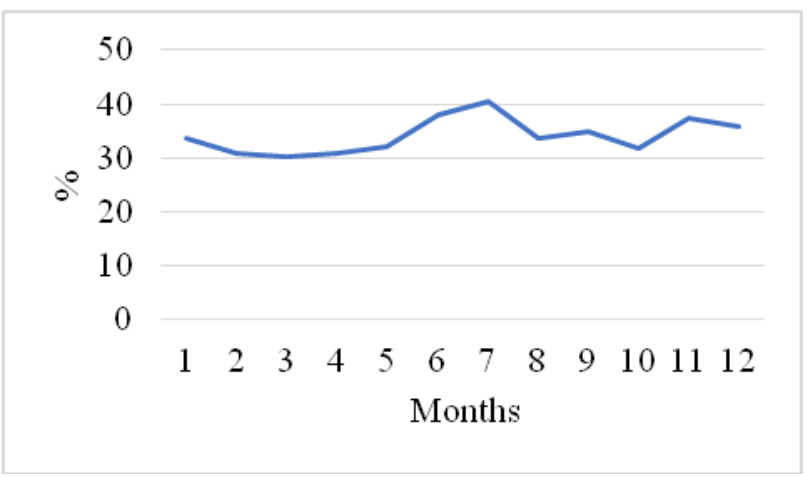

Fig. 4. Annual pattern of daily precipitation frequency in the Bydgoszcz region (1971-2013).

The data describing the daily precipitation efficiency was investigated in terms of probability distribution. For each month the compliance with gamma distribution was studied. Gamma distribution density with the probability density function in a form of:

$$
f(x)=\frac{1}{\beta^{\alpha} r(\alpha)} x^{\alpha-1} e^{-x / \beta}
$$

for $\mathrm{x}>0, \alpha>0, \beta>0$.

$\Gamma(\alpha)$ stands for the gamma function defined with the formula:

$$
\Gamma(\alpha)=\int_{0}^{\infty} x^{\alpha-1} e^{-x} d x
$$

The values of unknown parameters were estimated with the method of the highest credibility. The results of testing the compliance of the empirical data with gamma distribution are provided in Table 2. For every month results in the second and third columns of Table 2 provides estimated values of parameters $\alpha$ and $\beta$ of gamma distribution. Parameter a is the parameter of form (shape) and it does not show a high variation, whereas parameter of scale $\beta$ changes similarly as the mean value. Column 4 in Table 2 provides the values of testing statistics of Kolmogorov test $\lambda$. All the values are definitely lower than critical value $\lambda_{\text {crit }}=1.35$ at the significance level 0.05 . The fact confirms the daily compliance of the probability distribution of the value of daily precipitation efficiency for each month with gamma distribution.

Table 2. Estimation of gamma distribution parameters and Kolmogorov test $\lambda$.

\begin{tabular}{|c|c|c|c|}
\hline \multirow{2}{*}{ Month } & \multicolumn{2}{|c|}{ Distribution parameters } & Kolmogorov test \\
\cline { 2 - 4 } & $\alpha$ & $\beta$ & 0.28 \\
\hline 1 & 0.78 & 3.24 & 0.14 \\
\hline 2 & 0.76 & 2.99 & 0.50 \\
\hline 3 & 1.08 & 2.74 & 0.23 \\
\hline 4 & 0.65 & 4.10 & 0.28 \\
\hline 5 & 0.64 & 7.33 & 0.50 \\
\hline 6 & 0.69 & 6.87 & 0.56 \\
\hline 7 & 0.57 & 9.88 & 0.31 \\
\hline 8 & 0.70 & 7.68 & 0.37 \\
\hline 9 & 0.59 & 6.88 & 0.38 \\
\hline 10 & 0.61 & 5.63 & 0.33 \\
\hline 11 & 0.74 & 3.76 & 0.25 \\
\hline 12 & 0.82 & 3.60 & \\
\hline
\end{tabular}

Fig. 2 demonstrates that the mean values of daily precipitation efficiency for respective months can differ considerably. Fig. 5 presents the plots of empirical distribution functions for the precipitation recorded in January (Fe1) and July (Fe2). Distribution functions of the daily precipitation efficiency in January (Fe1) and July (Fe2) were compared with Kolmogorov-Smirnov test $\lambda$ (test of comparison of two empirical distribution functions for large statistical samples). Calculated statistics value $\lambda=3.17$. The value definitely exceeds the values provided in statistical tables, which allows for rejecting the hypothesis about the equality of distribution functions.

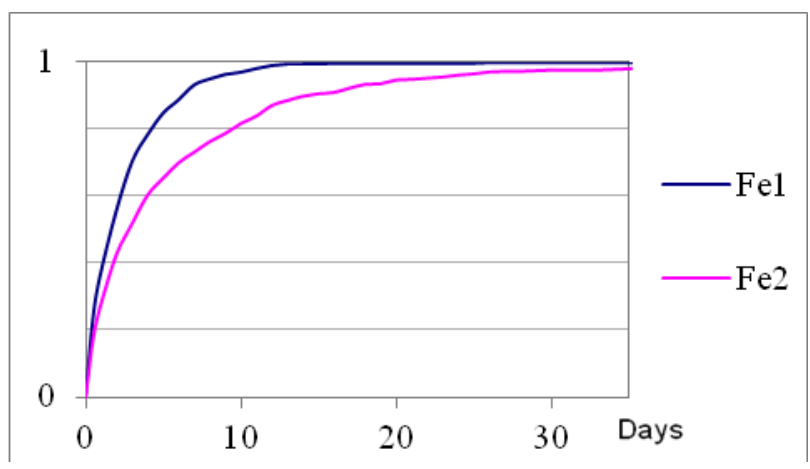

Fig. 5. Comparison of empirical distribution functions for daily precipitation in January (Fe1) and July (Fe2). 


\section{Summary}

The paper presents characteristics with standard methods of the daily precipitation measured in the Bydgoszcz region in 1971-2013. There was found a high dependence of the indicators studied on the month, confirming the annual pattern typical for the transitional climate of the temperate zone. In general, it demonstrates the advantage of the amount and variation, and less considerably - daily precipitation in summer months, as compared with the winter months. The probability distribution of the daily precipitation amount for each month was compliant with the gamma distribution, which allows for determining a potential variation in the future. However, one must agree with the opinion by Gregorczyk and Michalska [16] that predicting the precipitation distribution with mathematical models is difficult due to a high natural precipitation variation and the need of making many assumptions which can change in the period covered by the simulation.

Research was made within the framework of the FACCE JPI MACSUR project titled: Modelling European Agriculture with Climate Change for Food Security Acronym FACCE MACSUR 2 realized between 01/06/2015 and 31/05/2017

\section{References}

1. K. Chmura, E. Chylińska, Z. Dmowski, L. Nowak, Infr. Ecol. Rur. Area 9, 33-44 (2009)

2. W. Bojar, J. Żarski, R. Verburg, F. Brouwer, Studies \& Proceedings of Polish Association for Knowledge Management 61, 29-45 (2012)

3. W. Bojar, L. Knopik, J. Żarski, Studia Mater Pol Stow Zarz Wiedzą 64, 31-44 (2013)

4. J. Żarski, S. Dudek, R. Kuśmierek-Tomaszewska, W. Żarski, Infr. Ecol. Rur. Area II/2, 813-824 (2017)

5. B. Bąk, Woda-Środowisko-Obszary Wiejskie 9, 1138 (2003)

6. J. Żarski, S. Dudek, Zesz. Nauk. ATR 217/43, 4351 (1999)

7. J. Żarski, S. Dudek, Zesz. Nauk. WSHE VI, 85-98 (2000)

8. J. Żarski, S. Dudek, R. Kuśmierek-Tomaszewska, W. Bojar, L. Knopik, W. Żarski, Infr. Ecol. Rur. Area II/3, 643-656 (2014)

9. L. Kuchar, S. Iwański, Infr. Ecol. Rur. Area I/2, 187-200 (2013)

10. R. Twardosz, Prace Geogr. IGGP UJ 105, 19-71 (2000)

11. K. Krężałek, T. Szymczak, B. Bąk, WodaŚrodowisko-Obszary Wiejskie 44, 77-90 (2013)

12. J. Jędruszkiewicz, M. Zieliński, Acta Geogr. Lodz. 104, 201-211 (2016)

13. R. Twardosz, The synoptic and probabilistic aspects of diurnal precipitation variation in Cracow (18862002) (IGiGP UJ, Kraków, 2005)
14. R. Kuśmierek-Tomaszewska, J. Żarski, S. Dudek, Comput Electron Agric. 88, 44-51 (2012)

15. B.J. Garnier, Basics of climatology (IMGW, Warszawa, 1996)

16. A. Gregorczyk, B. Michalska, Folia Pomeranae Univ Technol Stetinensis, Agric Piscaria Zootech 290(20), 25-32 (2011) 